\title{
Atualização em COVID-19: manifestações do coronavírus e suas implicações oftalmológicas
}

COVID-19 update: manifestations of the coronavirus and its ophthalmological implications

Actualización COVID-19: manifestaciones del coronavirus y sus implicaciones oftalmológicas

Rafael Barbosa Silveira1*, Maria Clara Campos Diniz Duarte ${ }^{1}$, Regiane Helena Medeiros Braga ${ }^{2}$, Sara Gabriele Vieira ${ }^{3}$, Vitória Augusto Santos ${ }^{3}$, Matheus Caldas Santos Carvalho ${ }^{3}$, João Caetano Barbosa Duarte ${ }^{4}$, Ana Carolina Canedo ${ }^{5}$.

\section{RESUMO}

Objetivo: Elucidar os estudos que corroboram para as manifestações do novo coronavírus e suas manifestações clínicas oftalmológicas, bem como suas complicações. Revisão bibliográfica: Frente a necessidade de compreender melhor o vestígio da COVID-19 no organismo humano, em uma observação intervencional realizada com trinta pacientes com pneumonia por SARS-CoV-2, evidenciou que o vírus estava presente nas lágrimas e secreções conjuntivais dos indivíduos com conjuntivite. Apesar de termos indícios oftalmológicos que evidenciam a manifestação do vírus tais dados ainda se mostram insuficientes. Ademais, salienta-se que vários são os desfechos clínicos nos pacientes infectados, se comparados com aqueles indivíduos não contaminados. Considerações finais: Sabe-se que a principal via de contágio do SARS-COV2 é respiratória, mas estudos científicos atuais indicam que o vírus pode ser transmitido também através de lágrimas. Porém, as evidências sobre a COVID-19 no âmbito oftalmológico ainda são limitadas, logo há a necessidade de realizar novas pesquisas para elucidar de forma mais clara a sua forma de transmissão pela via ocular.

Palavras-chave: Doença por Coronavírus 2019-nCoV, Oftalmologia, Infecções por coronavírus, Saúde ocular.

\begin{abstract}
Objective: To elucidate the studies that confirm the new coronavirus manifestations and its ophthalmological clinical symptoms, as well as its complications. Literature review: Faced with the need to better understand the trace of COVID-19 in the human body, an interventional observation carried out with thirty patients with SARS-CoV-2 pneumonia showed that the virus was present in the tears and conjunctival secretions of individuals with conjunctivitis. Although there is ophthalmological evidence which confirms the manifestation of the virus, this data is still insufficient. Furthermore, it is important to emphasize that there are several clinical outcomes in infected patients, when compared to those uncontaminated individuals. Final considerations: It is known that the main route of transmission of SARS-COV-2 is respiratory, but current scientific studies indicate that the virus can also be transmitted through tears. However, the evidence on COVID-19 in the ophthalmological scope is still limited, so there is a need for further research to elucidate its form of transmission through the ocular route.
\end{abstract}

Key words: Coronavirus disease 2019-nCoV, Ophthalmology, Coronavirus infections, Eye health.

\footnotetext{
1 Faculdade de Minas (FAMINAS - BH), Belo Horizonte - MG. *E-mail: rafaelbsmed@gmail.com

2 Pontifícia Universidade Católica de Minas Gerais (PUC MINAS), Betim - MG.

${ }^{3}$ Faculdade da Saúde e Ecologia Humana (FASEH), Vespasiano - MG.

${ }^{4}$ Centro Universitário de Belo Horizonte (UNI - BH), Belo Horizonte - MG.

${ }^{5}$ Santa Casa de Misericórdia de Belo Horizonte (SCM - BH), Belo Horizonte - MG.
} 


\section{RESUMEN}

Objetivo: Dilucidar los estudios que corroboran las manifestaciones del nuevo coronavirus y sus manifestaciones clínicas oftalmológicas, así como sus complicaciones. Revisión de la literatura: Dada la necesidad de comprender mejor el rastro de COVID-19 en el cuerpo humano, una observación intervencionista realizada con treinta pacientes con neumonía por SARS-CoV-2 mostró que el virus estaba presente en las lágrimas y secreciones conjuntivales de individuos con conjuntivitis. A pesar de que tenemos evidencia oftalmológica que evidencia la manifestación del virus, dichos datos aún son insuficientes. Además, cabe señalar que hay varios resultados clínicos en los pacientes infectados, en comparación con los individuos no contaminados. Consideraciones finales: Se sabe que la principal vía de contagio del SARS-COV-2 es respiratoria, pero los estudios científicos actuales indican que el virus también se puede transmitir a través de las lágrimas. Sin embargo, la evidencia sobre el COVID-19 en el ámbito oftalmológico aún es limitada, por lo que es necesario realizar más investigaciones para dilucidar con mayor claridad su forma de transmisión por vía ocular.

Palabras clave: Enfermedad por coronavirus 2019-nCoV, Oftalmología, Infecciones por coronavirus, Salud ocular.

\section{INTRODUÇÃO}

O surto de pneumonia relatado no final de 2019 na cidade de Wuhan, na China, foi só o início do momento totalmente atípico que surpreendeu a população a nível mundial. Declarada pela Organização Mundial de Saúde (OMS) como uma Emergência em Saúde Pública de Interesse Mundial em 31 de janeiro de 2020 e em 11 de março de 2020 como Pandemia, a infecção pelo novo Coronavírus (COVID-19) representa hoje o principal e mais complexo problema de saúde no Brasil e no mundo (DO MONTE LM, et al., 2020).

Em 6 de abril de 2020, cerca de 65 dias após a primeira declaração da OMS sobre o vírus, já havia um total de 1.136.862 de casos ao redor do mundo (AIELLO F, et al., 2020). A corrida científica buscando entender a fisiopatologia do vírus, as formas de transmissão e contágio, o melhor diagnóstico, o tratamento e as medidas preventivas desde então não pararam, e pesquisas nos mais diversos campos da saúde buscam contribuir nas descobertas das implicações do Novo Coronavírus (DO MONTE LM, et al., 2020).

Cursando com sintomas que variam desde um quadro semelhante a um resfriado até uma síndrome respiratória aguda grave, a infecção pelo COVID-19 vem sendo alvo de pesquisas e descobertas das mais diferentes áreas da saúde, isso em virtude dos atuais relatos sobre suas manifestações em nível sistêmico. Nesse contexto, surgem informações, estudos e consequentes publicações em revistas como o Journal of Medical Virology, que relacionam as manifestações na superfície ocular com o coronavírus. No momento, há demasiadas controvérsias com relação à contaminação, transmissão e evolução da infecção por COVID-19 por meio da superfície ocular. Entretanto, não se descarta tal hipótese devido a evidências como a existência de receptores para o Coronavírus nas células dendríticas da córnea e estudos comprovaram a existência do vírus no fluido lacrimal, havendo relatos de conjuntivite como sendo a primeira manifestação da doença (XIA JMM, et al., 2020).

Diante disso, a presente revisão bibliográfica teve por objetivo recolher e sintetizar o máximo de informações no que tange a transmissão do Coronavírus por meio da mucosa ocular, bem como suas manifestações clínicas oculares e suas complicações. Ademais, almejou-se entender e explanar sobre o papel do oftalmologista no contexto da pandemia, os riscos que esses profissionais estão inseridos tal qual a exposição de seus pacientes. Dessa forma, o trabalho se justifica na medida em que vem abordar a relação do Novo Coronavírus com a superfície ocular e as possíveis implicações ocasionados pela doença.

\section{REVISÃO BIBLIOGRÁFICA}

A pandemia do novo Coronavírus trouxe estigmas e especulações à sociedade de oftalmologia, e isso motivou uma busca inesgotável por respostas e evidências concretas. Sabemos que as explicações 
existentes, atualmente, ainda são limitadas, sendo que há escassez de casos relacionados à contaminação pela via ocular e às manifestações clínicas visuais, as quais precisam ser entendidas e estudadas. Além disso, no que diz respeito ao manejo das consultas oftalmológicas, são necessárias medidas que ofereçam proteção ao profissional e ao paciente (EMPARAN JPO, et al., 2020).

Frente a esse cenário, para a validação das informações é preciso discorrer brevemente sobre o Coronavírus: trata-se de um vírus de RNA de fita positiva capaz de causar doenças em seres humanos e outros animais. Estudos observaram que a sequência de RNA do COVID-19 assemelha se a de dois coronavírus de morcego, tendo como hipótese que esses animais sejam a fonte primária da infecção (MCLNTOSH K, 2020). Os tipos de coronavírus humanos conhecidos são: hCoV229E, OC43, NL63 e HKU1, os quais geralmente causam doenças respiratórias leves, são sazonais e existem na sociedade há anos.

De certa forma, os vírus precisam se ligar às células hospedeiras, invadi-las e, concomitante, iniciar sua replicação. Por conseguinte, no processo de contágio celular, o vírus do COVID-19 utiliza a proteína spike preparada por meio do envelope lipídico no qual se liga a vários receptores ao mesmo tempo disponíveis nas células hospedeiras (YAN R, et al., 2020). Sendo assim, o SARS-CoV-2 usa a enzima conversora de angiotensina 2 (ACE2) como seu receptor nas células humanas, e sua ligação facilita a infecção. Em alguns estudos, foram observados que a serina protease de mamífero TMPRSS2 ou a protease Furin (também conhecida como Enzima de Clivagem de Aminoácidos Básicos emparelhados) parecem estimular a proteína spike para interação com a ACE2 (YAN R, et al., 2020).

Alguns autores acreditam que o vírus tem o potencial de se ligar ao receptor CD209, do SARS-CoV-2, presente nas células dendríticas da córnea. Ademais, a mucosa ocular, por ser extremamente vascularizada, pode ser sugestiva de uma zona de inoculação direta do vírus por gotículas infectadas, assim como a possibilidade da entrada do vírus pelo ducto lacrimal e sua dispersão no trato aéreo superior. Desta maneira, é relevante à amplificação de estudos frente a essas perspectivas para que medidas de proteção no âmbito da oftalmologia sejam tomadas o quanto antes (WILLCOX MDP, et al., 2020).

Um dos principais meios de difusão da infecção pelo SARS-CoV-2 na população é o contato direto com os indivíduos infectados por meio da dispersão de gotículas ao falar, tossir e espirrar, ressaltando que as pessoas assintomáticas também podem disseminar o vírus, tornando-se uma potencial fonte de transmissão (EMPARAN JPO, et al., 2020). Todavia, esta infecção não se limita ao trato respiratório e a contaminação também ocorre por contato direto ou indireto com mucosas como as dos olhos, da boca ou do nariz, o que é evidenciado pela estabilidade viral em aerossóis em diferentes superfícies (AMESTY MA, et al., 2020).

Estudos levantados até o presente momento sugeriram três teorias em relação à entrada do vírus no organismo humano: inserção direta na conjuntiva por meio de gotas contaminadas com o patógeno, dispersão do microrganismo nas vias aéreas superior por meio do ducto nasolacrimal ou por contaminação hematogênica da glândula lacrimal (SEAH I e AGRAWAL R, 2020).

Sabidamente, essas suposições têm uma forte ligação com as principais informações repassadas pelos Órgãos Governamentais, por isso, até a confirmação das evidências faz se necessário a manutenção dos cuidados individuais contra a contaminação pelo COVID-19. Além disso, pesquisas recentes ainda consideram a rota fecal-oral como possível fonte de transmissão, sendo associados sintomas entéricos (diarreia, náusea, vômitos) à infecção por COVID-19 (AMESTY MA, et al., 2020).

A porcentagem de pacientes que apresentaram partículas virais evidenciadas nas lágrimas ou na conjuntiva apresentou variação entre 0 a 7.14\% nos treze estudos analisados por Emparan JPO, et al. (2020). Outro exemplo de observação prospectivo intervencional conduzido por Xie X, et al. (2020), realizado com trinta pacientes diagnosticados com pneumonia por SARS-CoV-2, evidenciou que o vírus estava presente nas lágrimas e secreções conjuntivais dos indivíduos com conjuntivite, entretanto não houve deteç̧ão do vírus nas lágrimas ou secreções conjuntivais dos pacientes sem conjuntivite.

Essa observação sugere que as secreções lacrimais e conjuntivais não se configuram como uma via de entrada comum de transmissão para o novo vírus do coronavírus, levando em consideração que a maioria dos pacientes não apresentaram conjuntivite. Ainda assim, tal via de transmissão não pode ser 
completamente eliminada nesses pacientes, e qualquer sinal de conjuntivite no atual contexto clínico deve ser considerado como possível infecção por coronavírus, principalmente se acompanhado por sintomas como coriza, dor na garganta ou febre (BOZKURT B, et al., 2020).

Desta forma, as publicações sobre os mecanismos patogênicos do SARS-CoV-2 até o momento são limitadas, principalmente no que diz respeito ao tecido ocular. Contudo, estudos genômicos e estruturais mostram que o vírus apresenta um receptor que o permite infectar as células hospedeiras através da enzima conversora de angiotensina 2 (ECA2) (SEAH I e AGRAWAL R, 2020).

Diante dessa conjuntura, vale destacar que o sistema renina-angiotensina-aldosterona apresenta funções autócrinas complexas em tecidos específicos, tais como o olho, no qual foi identificado a ECA2 no humor aquoso do ser humano. No entanto, a presença de tal enzima na conjuntiva e na córnea ainda não foi determinada pelas evidências. Assim, são necessários aprofundamentos de estudos relacionados a essas manifestações oftalmológicas para elucidar tal hipótese (SEAH I e AGRAWAL R, 2020).

Apesar da infecção pelo novo Coronavírus ser majoritariamente assintomática ou leve ( $80 \%$ dos casos), ela pode levar à pneumonia grave e morte. Estas condições referem a infecção por parte de indivíduos que se enquadram nos grupos de riscos e/ou com alguma comorbidade, como por exemplo aqueles com mais de 60 anos de idade ou com doenças prévias, como doença cardiovascular, hipertensão, doença pulmonar crônica e câncer (BOZKURT B, et al., 2020).

Ademais, o estudo publicado pelo New England Journal of Medicine esclarece os indícios clínicos dentre os infectados, foram avaliados os sintomas clínicos de 1.099 pacientes hospitalizados com COVID19 em 522 hospitais da China até janeiro. Os pesquisadores observaram um período médio de incubação de 4 dias até o aparecimento dos sintomas pelo Coronavírus. O sintoma mais comum foi a febre, presente em $43,8 \%$ dos admitidos, evoluindo para $88,7 \%$ durante a internação. Concomitante o segundo sintoma mais comum aos infectados foi a tosse $(67,8 \%)$, seguido de náusea ou vômito (5\%) e diarreia (3,8\%) (GUAN W, et al., 2020).

Além destes dados, outras linhas de pesquisa foram abordadas no estudo supracitado, como a idade média dos pacientes infectados ( 47 anos) e o sexo ( $41,9 \%$ do sexo feminino), isso evidencia a prevalência de homens dentre os contaminados. Outro quesito importante analisado foi a presença de comorbidades dentre a população geral do estudo, $23,7 \%$ dos pacientes internados tinham pelo menos uma doença coexistente de risco (GUAN W, et al., 2020).

Ademais, na admissão dos pacientes foi identificado a linfocitopenia em $83,2 \%$ da população, já a trombocitopenia estava presente em $36,2 \%$ e a leucopenia em $33,7 \%$ (presente em pacientes graves). Ainda, o aumento dos níveis de PCR na maioria dos pacientes, já os níveis elevados de alanina aminotransferase, aspartato aminotransferase, creatina quinase e d-dímero foram menos comuns. Todavia, em relação às alterações nos exames de imagem dos pulmões, sabe-se que os padrões mais comuns presentes na Tomografia Computadorizada (TC) foram a opacidade em vidro fosco $(56,4 \%)$ e o sombreamento bilateral irregular (51,8\%) (GUAN W, et al., 2020).

Por outro lado, as manifestações nas infecções assintomáticas são consideradas como sintomas leves ou a inexistência deles, isso pode ser explicado por uma resposta imune específica do indivíduo. Logo, esta resposta gera danos teciduais menores que inibiram o aparecimento de sintomas (BOZKURT B, et al., 2020).

Consequentemente, os infectados podem apresentar fases assintomáticas e sinais e sintomas habituais como febre alta e dispneia, dentre outros, além de manifestarem condições atípicas como anosmia, manifestações cutâneas, alterações renais, dor abdominal e acometimento ocular (DO MONTE LM, et al., 2020).

Logo, a escassez nas evidências oftalmológicas é um ponto relevante para a elucidação das manifestações oculares, mas pesquisas apontaram a presença de sinais como congestão conjuntival em pacientes infectados. Dentre esses indícios, as manifestações presentes na mucosa visual incluem a hiperemia, a quemose, a epífora e o aumento de secreções oculares. Há uma correlação entre a intensidade da doença e os sintomas oftalmológicos, os pacientes que apresentaram esses sinais tiveram um aumento 
nas células sanguíneas, PCR e lactato desidrogenase, corroborando para o estado patológico do indivíduo como grave (SIEDLECKI J, et al., 2020).

Todavia, essas informações incomuns necessitam de posterior explanação, principalmente as implicações oftalmológicas, sendo que estas, além de caracterizar a gravidade do Coronavírus, deixam os profissionais vulneráveis à contaminação, haja vista que os atendimentos aos pacientes oftalmológicos são feitos com uma proximidade inferior a 1 metro. Portanto, faz se necessário, até o desenvolvimento de novas pesquisas sobre os indícios oculares, a utilização de insumos de proteção individual aos especialistas em oftalmologia, assim como a adoção de medidas de proteção instauradas pelo Ministério da Saúde (BRASIL MS, 2020).

No que diz respeito ao diagnóstico da infeç̧ão por SARS-CoV-2, a Comissão Nacional de Saúde da China posiciona os exames laboratoriais como ferramenta padrão para o mesmo, incluindo a realização de testes de swab nasofaríngeo e orofaríngeo. Dentre os testes diagnósticos disponíveis têm-se: reação em cadeia da polimerase com transcrição reversa (RT-PCR), RT-PCR em tempo real ( $r R T-P C R$ ) e amplificação isotérmica mediada por loop de transcrição reversa (RT-LAMP), todos com intuito de identificar a presença do vírus no organismo humano (ZHAI P, et al., 2020).

Todavia, o tempo prolongado para liberação dos resultados dos testes laboratoriais e a escassez de kits comerciais geram atraso no diagnóstico. Sendo assim, em pacientes apresentando febre, dor de garganta, fadiga, tosse ou dispnéia associados à exposição recente ao vírus, o diagnóstico se dá através de achados típicos na TC de tórax, mesmo com resultados negativos da RT-PCR. Os achados típicos da TC incluem vidro fosco parenquimatoso pulmonar bilateral e opacidades pulmonares consolidadas, ocasionalmente com morfologia arredondada e distribuição pulmonar periférica. Dessa forma, a combinação dos exames de imagem com os achados clínicos e laboratoriais têm o potencial de facilitar o diagnóstico precoce da pneumonia por COVID-19 (XIE X, et al., 2020).

Considerando-se que ainda são necessárias elucidações no que diz respeito às implicações oftalmológicas da infecção por SARS-CoV-2, dificulta-se a determinação de um tratamento específico para a conjuntivite viral associada ao vírus em questão. Os estudos existentes são limitados e não há um antiviral ocular específico que busque reduzir a possível carga viral na conjuntiva e a transmissão na perspectiva oftalmológica (AMESTY MA, et al., 2020).

Assim, como tratamento para o COVID são utilizadas drogas antivirais sistêmicas como umefenovir, lopinavir e ritonavir, todavia estes fármacos não são específicos para a patologia na via ocular. E levando em conta que o tratamento da conjuntivite viral é constituído majoritariamente por medidas de suporte e a maioria dos casos são autolimitados, o foco deste no atual contexto deve ser diminuir a possível carga viral na conjuntiva e o potencial de transmissão através das secreções oculares e lacrimais (LABIB BA, et al., 2020).

Diante desse contexto, podem ser adotadas recomendações oftalmológicas gerais para a conjuntivite viral, como medidas higiênicas (lavagem das mãos, especialmente, na aplicação de colírios ou manuseio de lentes de contato; evitar tocar ou esfregar os olhos; trocar fronhas, lençóis, toalhas, regularmente etc.) (LABIB BA, et al., 2020). Ademais, devido à escassez das evidências sobre a transmissão do SARS-CoV-2 através do tecido ocular, não é possível estabelecer sua capacidade de infectar estruturas oculares e habilidade de colonizar apenas ou de invadi-la, induzindo a conjuntivite (AIELLO F, et al., 2020).

Considerando esses fatores, os médicos devem permanecer vigilantes no reconhecimento de manifestações precoces e atípicas do COVID-19, incluindo o envolvimento inflamatório ocular como uma possível manifestação. A proteção individual é inquestionável e equipamentos de proteção que cubram a boca, o nariz e os olhos dos médicos são indispensáveis, especialmente em encontros clínicos (CHEN MJ, et al., 2020).

A natureza do exame ocular exige a proximidade entre o oftalmologista e o paciente. Levando em consideração a principal forma de transmissão, via gotículas respiratórias, muitos países interromperam temporariamente as consultas de rotina e implementaram novas medidas devido ao risco de transmissão. $O$ exame presencial passou a ser necessário somente no caso de emergência ocular presumida, mesmo assim após uma consulta remota inicial por telefone ou outro meio eletrônico (BOZKURT B, et al., 2020). 
Nessa situação os oftalmologistas foram aconselhados a tomar precauções importantes como: garantia do bom estado do paciente, uso de equipamento de proteção individual, instalação de escudo protetor no biomicroscópio da lâmpada de fenda e higienização completa das mãos e de todas as superfícies antes de depois da visita. Estas precauções visam a proteção do médico e do paciente, devendo permanecer em vigor até o momento que a pandemia tenha sido controlada ou até que outras medidas possam ser implementadas (WILLCOX MDP, et al., 2020).

\section{CONSIDERAÇÕES FINAIS}

Diante do exposto, fica claro que as evidências sobre as implicações da COVID-19 no âmbito oftalmológico ainda são esporádicas e, por sua vez, é de extrema relevância a ampliação de pesquisas nessa área. As provocações incitadas nos remete aos principais achados oculares, que são decorrentes da manifestação da COVID-19. Esses indícios passam a ser pontos de alerta aos oftalmologistas que ainda exercem suas consultas presenciais e, a proximidade do profissional para desenvolver o atendimento aumenta a sua exposição. Dessa forma, as medidas protetivas e as recomendações oftalmológicas são fundamentais para o controle da disseminação do vírus, bem como para orientar, o médico e o paciente, como proceder durante a assistência, independente da condição clínica que o paciente se encontra.

\section{REFERÊNCIAS}

1. AIELLO F, et al. Coronavirus 2019 (SARS-CoV-2) and colonization of tissues and eye sections: a systematic review. The Royal College of Ophthalmologists Eye, 2020; 34: 1206-1211.

2. AMESTY MA, et al. COVID-19 Disease and Ophthalmology: An Update. Ophthalmology and Therapy, $2020 ; 1$.

3. BOZKURT B, et al. The COVID-19 Pandemic: Clinical Information for Ophthalmologists. Turkish Journal of Ophthalmology, 2020; 50(2): 59.

4. BRASIL. Ministério da Saúde. Protocolo de Tratamento do Novo Coronavírus (2019-nCoV). Secretaria de Atenção Especializada à Saúde, Departamento de Atenção Hospitalar, Domiciliar e de Urgência, Coordenação-Geral de Urgência. Portal de Arquivos Saúde. Força Nacional do Sistema Único de Saúde (FN-SUS), Brasília/DF, 2020. Disponível em: http//www.saude.gov.br. Acessado em: 20 de julho de 2020.

5. CHEN MJ, et al. Precaution and prevention of coronavirus disease 2019 infection in the eye. Journal of the Chinese Medical Association. Wolters Kluwer Public Health Emergency Collection, 2020; 10:1097.

6. DO MONTE LM, et al. Atypical complications and clinical epidemiological characteristics of COVID 19: integrative review. Electronic Journal Collection Health. Revista Eletrônica Acervo Saúde, 2020; 46: e3699 - e3699.

7. EMPARAN JPO, et al. COVID-19 and the eye: how much do we really know? A best evidence review. Arquivos Brasileiros de Oftalmologia, 2020; 83(3): 250-261.

8. GUAN W, et al. Clinical characteristics of coronavirus disease 2019 in China. The New England journal of medicine, 2020; 382(18): 1708-1720.

9. LABIB BA, et al. Management of Adenoviral Keratoconjunctivitis: Challenges and Solutions. Magazine Clinic Ophthalmol. Dovepress, 2020; 17(14): 837-852.

10. MCLNTOSH K. Coronavirus disease 2019 (COVID-19): epidemiology, virology and prevention. Arquivo uptodate, 2020.

11. SEAH I, AGRAWAL R. Can the coronavirus disease 2019 (COVID-19) affect the eyes? A review of coronaviruses and ocular implications in humans and animals. Ocular immunology and inflammation, 2020; 28(3): 391-395.

12. SIEDLECKI J, et al. COVID-19: Ophthalmological Aspects of the SARS-CoV 2 Global Pandemic. Journals Thieme Übersicht. Klin Monatsbl Augenheilkd, 2020; 237: 1-6.

13. VAN HL, et al. Identification of a new human coronavirus. Nature Medicine Journal, 2004; 10(4): 368-73.

14. XIA JMM, et al. Evaluation of coronavirus in tears and conjunctival secretions of patients with SARS-CoV-2 infection. Journal of Medical Virology. Wiley Periodicals, 2020; 92: 589-594.

15. XIE X, et. al. Chest CT for Typical Coronavirus Disease 2019 (COVID-19) Pneumonia: Relationship to Negative RTPCR Testing. Europe PMC. Radiology, 2020; 296(2): E41-E45.

16. WILLCOX MDP, et al. The ocular surface, coronavirus and COVID - 19. Journal List, Wiley Public Health Emergency Collection,2020; 13:10.1111/cxo.13088.

17. YAN R, et al. Structural basis for the recognition of SARS-CoV-2 by full-length human ACE2. Revista Science.Ciência, 2020; 367(6485): 1444-1448.

18. ZHAI P, et al. The epidemiology, diagnosis and treatment of COVID-19. International journal of antimicrobial agents, 2020; 55:105955. 